\title{
Evaluation for Consumer online Trust Based on Structural Equation Modeling and Path Analysis
}

\author{
Kai Zhang \\ Correction Department of Education, The Central Institute for Correctional Police, \\ Baoding, China
}

\begin{abstract}
E-commerce success, especially in the B2C area, is determined in part by whether consumers trust sellers and products they cannot see or touch, and electronic systems with which they have no previous experience. This paper constructs the evaluation of consumer online trust index model based on Structural Equation Modeling (SEM). The best iterative initial values for Partial Least Square (PLS) estimation algorithm was put forward, which can enhance the speed of computation. With our model, the relationship of construction variables in consumer online trust evaluation indexes system can be analyzed, as well as the relationship between the construction and observation variables, also formula to calculate the electronic commerce trust index is provided in the paper. Consequently, consumer online trust can be analyzed efficiently, and efficient measures can be adopted to improve the consumer online trust, so that EC can develops more quickly.
\end{abstract}

Keywords: $\quad$ E-commerce; Trust; Structural Equation Modeling (SEM); Best Iterative Initial Values

\section{Introduction}

Currently, most Internet users still do not want to get in line to buy goods or services. Lack of trust is the consumer willing to trade online the main reason. Trust is the uncertainty and dependence of many social interaction is an important factor. However, due to online interaction and exchange relationships not only has high level of uncertainty, but also has anonymous, difficult to control and potential opportunism and other characteristics, risk and trust become crucial factor e. As the network of information technology in the business in the use of business becomes more complex : the exchange of goods and capital separate transactions require consumers to provide a variety of private sensitive information ( address, phone number, credit card number, etc. ), etc., and many consumers preserve their private information network technology capability and credibility of online merchants worried. In recent years, researchers have trust issues in ecommerce for a lot of discussion, mostly case studies and empirical research methods. Luyao Bin, Zhou Tao studied the B2C environment influence consumers online initial trust factor; Herman Cho, etc. for consumer trust in online transactions empirical analysis of influencing factors. There is a lack of 
trust in e-commerce analysis of a generic model, the model will be applied to further quantify the study to measure the trust less.

Structural equation modeling is a measure of the correlation between the variables a good model, derived from the structural equation model of customer satisfaction model is a better measure of customer satisfaction model. Here we combine e-commerce trust in the specific circumstances, given structural equation model $\mathrm{B} 2 \mathrm{C}$ e-commerce trust metric theory.

\section{The Influencing Factors of Consumer Online Trust}

Now there are many e-commerce trust literature concerns the impact factor. One representative is Urban et al large sample empirical studies conducted. Conclusion: Website features and characteristics of both consumers affect consumer confidence, which features in the website impact on trust in descending order of priority to: navigation, brand, advice, privacy and security, site errors, order fulfillment and third-party certification; consumer characteristics in the degree of influence on trust in descending order: online experience, to understand the extent of the network, online leisure and shopping experience. Lee and Turban that the factors affecting e-commerce trust trustworthiness of online vendors (including capacity, honesty and goodwill), the trustworthiness of shopping online media (including technical capability, reliability and media conditions) and safety factor (including third-party certification and safety measures, etc.), in addition, through the influence of individual trust propensity effects of these factors on trust.

To sum up research on online trust, the paper that can be factors that influence consumers online trust is divided into four parts, shown in Figure 1.

Website image ( including site functionality, network technology ), consumer's personal characteristics, business reputation and customer satisfaction, in which the first two were in addition to a direct effect on online trust, but also an indirect effect by acting on customer satisfaction in online trust. Customer satisfaction is a product, a service of the positive evaluation, even if an enterprise customer satisfaction is only accepted based on their products and services to his satisfaction, it is an emotional evaluation. Customer trust is the customer of the brand products as well as the trust that owns the brands sense that they can rationally face brand business success and unfavorable, so customer satisfaction is the customer premise of mutual trust, customer trust is the result of customer satisfaction.

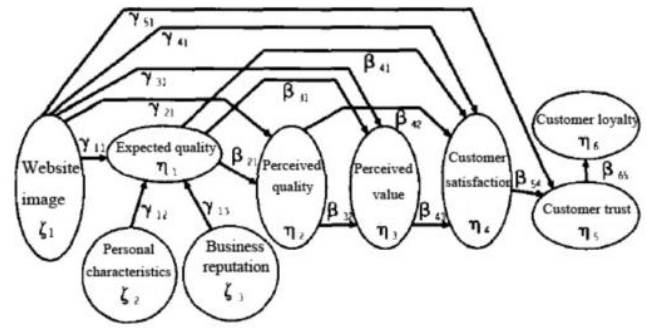

Fig.1. E-commerce trust model of the structure

In addition, consumers personal characteristics also influence consumer online trust. Consumers' personality traits ( including his ( or her ) life and values, consumer attitudes ), income, pretransaction experience will affect his ( or her ) on the trust in online transactions.

According to Parasurama, who in the 1980s proposed SERVQUAL model determines the level of customer perceived quality assessment of the quality of the customer, and the customer service process depends on the perceived quality of the customer experience in customer service expectations and the 
difference between extent. For online trading customers, they can not directly feel the seller's service network

Station 's image will directly affect their satisfaction, in addition to the quality of their expectations, perceived quality, perceived value will affect their satisfaction.

Customers trust the results will lead directly to customer retention (Retainment) or a customer loyalty.

\section{Customers Online Trading Trust Structure Model and Its Algorithm}

Based on the above analysis, structural equation modeling, we give in Figure 1 B2C e-commerce trust structure model. We selected nine latent variables (Latent Variables). Three independent variables : website image A, personal characteristics $\mathrm{A}$, and business reputation A; six dependent variables : the expected quality A, perceived quality $A$, perceived value A, Customer Satisfaction A, Customer Trust A, Customer Loyalty A. Each latent variable and set some explicit in the variable (Manifest Variables that observed variables : observation Variables).

Here the design customer trust structure model selected three independent variables, the expected quality of a dependent variable observed variable is not set, it is measured by means of three independent variables. This makes it easy to analyze three independent variables on the impact of customer trust in online transactions. Dependent variable the expected quality, perceived quality and perceived value does not directly affect online trust, both to influence online trust through customer satisfaction.

From the literature on the analysis of customer trust, we will customers trust into cognitive trust, emotional trust and behavior trust. Cognitive trust, based on products and services directly to the formation, since such products and services just to meet his individual needs, this trust is resident in the basic level, it may be because of inclination, the shifting environment; emotional trust in the use of products and services obtained after lasting satisfaction, it is possible to form preferences for products and services; behavior trust only in enterprises to provide products and services to become an integral part of customer needs and enjoyment, the behavior trust will form, its performance is maintain long-term relationships and repeat purchases, as well as corporate and product focus, and strengthen trust in this concern to find the information or proof of no confidence against wronged information.

The figure above shows the structural equation can be expressed as :

$\left(\begin{array}{l}\eta_{1} \\ \eta_{2} \\ \eta_{3} \\ \eta_{4} \\ \eta_{5} \\ \eta_{6}\end{array}\right)=\left(\begin{array}{cccccc}0 & 0 & 0 & 0 & 0 & 0 \\ \beta_{21} & 0 & 0 & 0 & 0 & 0 \\ \beta_{31} & \beta_{32} & 0 & 0 & 0 & 0 \\ \beta_{41} & \beta_{42} & \beta_{43} & 0 & 0 & 0 \\ 0 & 0 & 0 & \beta_{54} & 0 & 0 \\ 0 & 0 & 0 & 0 & \beta_{65} & 0\end{array}\right)\left(\begin{array}{l}\eta_{1} \\ \eta_{2} \\ \eta_{3} \\ \eta_{4} \\ \eta_{5} \\ \eta_{6}\end{array}\right)+\left(\begin{array}{ccc}r_{11} & r_{12} & r_{13} \\ r_{21} & 0 & 0 \\ r_{31} & 0 & 0 \\ r_{41} & r_{42} & 0 \\ r_{51} & r_{52} & r_{53} \\ 0 & 0 & 0\end{array}\right)\left(\begin{array}{l}\xi_{1} \\ \xi_{2} \\ \xi_{2}\end{array}\right)+\left(\begin{array}{l}\xi_{1} \\ \xi_{2} \\ \xi_{3} \\ \xi_{4} \\ \xi_{5} \\ \xi_{6}\end{array}\right)$

Where $\xi_{i}(i=1, \ldots, 6)$ is zero mean and variance are limited and are not associated with other variables, random error term. For the high-level structure variables, as well as relations:

$$
\left(\begin{array}{l}
\xi_{1} \\
\xi_{2} \\
\xi_{2}
\end{array}\right)=\left(\begin{array}{l}
\alpha_{11} \\
\alpha_{12} \\
\alpha_{13}
\end{array}\right) \eta_{1}+\left(\begin{array}{l}
v_{1} \\
v_{2} \\
v_{3}
\end{array}\right)
$$

If the structure variables observed variables corresponding to $\chi_{p q}, p=l, \ldots$, $S(q), q=l, 2,3$, and to $y_{i j}, j=l, \ldots, L(i), i$ $=2, \ldots, 6$ indicates. The figure shows the corresponding structure from the argument variables to the equation and the relationship between observed variables from the dependent variable structure variables corresponding to the 
relationship between observed variables equation can be expressed as:

$$
\begin{aligned}
& \left(\begin{array}{c}
x_{11} \\
x_{21} \\
x_{12} \\
x_{22} \\
x_{13} \\
x_{23}
\end{array}\right)=\left(\begin{array}{ccc}
\mu_{11} & 0 & 0 \\
\mu_{21} & 0 & 0 \\
0 & \mu_{12} & 0 \\
0 & \mu_{22} & 0 \\
0 & 0 & \mu_{13} \\
0 & 0 & \mu_{23}
\end{array}\right)\left(\begin{array}{l}
\xi_{1} \\
\xi_{2} \\
\xi_{2}
\end{array}\right)+\left(\begin{array}{c}
\delta_{11} \\
\delta_{21} \\
\delta_{12} \\
\delta_{22} \\
\delta_{13} \\
\delta_{23}
\end{array}\right) \\
& \left(\begin{array}{c}
y_{1 i} \\
\vdots \\
y_{j i}
\end{array}\right)=\left(\begin{array}{c}
\lambda_{1 i} \\
\vdots \\
\lambda_{j i}
\end{array}\right) \eta_{i}+\left(\begin{array}{c}
\varepsilon_{1 i} \\
\vdots \\
\varepsilon_{j i}
\end{array}\right) i=2, \ldots, 6
\end{aligned}
$$

Here, $\mu_{p q}, \lambda_{j i}$ are the load factor; $\delta_{k}(\mathrm{k}=1, \ldots, 6),{ }^{\varepsilon_{j i}}$ are not associated with other variables with zero mean and finite variance random error term. Conversely, from the observed variables to the structural relationship between the variables equation can be expressed as:

$$
\begin{gathered}
\xi_{q}=\sum_{j=1}^{S(q)} \varphi_{q j} x_{j q}+\varepsilon_{\zeta q}, q=1,2,3 \\
\eta_{i}=\sum_{j=1}^{L(i)} \omega_{i j} y_{j i}+\varepsilon_{\eta i}, i=2, \ldots, 6
\end{gathered}
$$

Here S (q), L (i) the q respectively represent the independent variables, the ith observation structure variables associated with the number of variables; $\varepsilon_{\zeta q}$ and $\varepsilon_{\eta i}$ is a random error term.

The model (1), (3) and (4) constitutes a structural equation model. Can be expressed in matrix form as: $\eta=B \eta+\tau \zeta+\zeta, X=\Lambda_{X} \zeta+\delta$.Wh ere $\Lambda_{X} \zeta, \delta$ is the coefficient matrix to be estimated.

\section{Conclusion}

This paper analyzes the impact of ecommerce trust factors, the introduction of an integrated structural equation modeling (SEM) to build online trust estimates reflected the improved application of partial least squares (PLS) algorithm, combined with improved sound and comprehensive electronic Business confidence index is calculated to evaluate the e-commerce trust index (ECTI). For the analysis of the factors affecting e-commerce trust and evaluation of customer trust a site of great significance. Calculations show that our algorithm is effective, convenient and effective.

\section{References}

[1] Grabner Krauters S. The Role of Consumers Trust in On-line Shopping. Journal of Business Ethics, 2002a,39(1):42-50.

[2] Reichheld F. Learning from Customer Defections [J].Harvard Business Review, 1999, ( 2 ) : 56-61.

[3] Baesens, Bart, Verstraeten et al. Bayesian network classifiers for identifying the slope of the customer lifecycle of long-life customers [J]. European Journal of Operational Research ( 2004 ),156 ( 2 ).

[4] Sum Kim, Kyung-Shik Shin, Kyungdo Park. An application of support vector machines for customer churn analysis: credit card case [C]. Advances in Natural Computation. First International Conference, ICNC 2005.

[5] G. L.Uthan, F. Sultan, W.J. Qualls. Placing Trust at the Center of Your Internet Strateg. Sloan Management Review, 2000, 42(1): 39-48. 